\title{
STAF EN LIJN IN DE PRACTIJK DER ADMINISTRATIEVE ORGANISATIE
}

\author{
door H. C. Verkerk
}

Men kan gevoegelijk zeggen dat de staf voor de administratieve organisatie bezig is, zich bij vele grote bedrijven burgerrecht te verwerven.

Het is er evenwel nog verre vandaan dat in de practijk van de administratie een duidelijk en eenstemmig inzicht bestaat in de inhoud en de betekenis van deze staffunctie, meer in het bijzonder in zijn verhouding tot de lijnfuncties.

Enige tijd geleden wijdde Prof. v. d. Schroeff in dit maandblad 1) een uitvoerige beschouwing aan het vraagstuk van staf en lijn in meer algemene zin 2 ), in welke beschouwing hij hetzelfde signaleerde.

In feite sprak v. d. Schroeff over de ,verwatering" van het begrip staf, als gevolg van de in de practijk bestaande neiging om allerlei niet rechtstreeks bij de uitvoering betrokken functionarissen als staffunctionaris te betitelen.

Zonder dientengevolge met de geciteerde uitspraak in conflict te komen, kan men ook in omgekeerde zin redeneren: mede omdat geen duidelijk beeld van het doelmatig stafbegrip voor ogen stond, kwam men er in de practijk toe, om ook niet-staffunctionarissen met de titel "staf" te tooien.

$E_{r}$ is als het ware een correlatief verband:

a. er bestaat geen duidelijke voorstelling van de doelmatige staffunctie, dientengevolge worden ook niet-staffuncties als zodanig aangeduid;

b. de practijk, niet-staffuncties nochtans als zodanig aanduidende, draagt er toe bij, dat het begrip ,staf" verwatert.

Het een gaat met het ander samen.

Zoals verder uit het betoog van Van der Schroeff blijkt, steekt achter de vaagheid van het begrip "staf" meer, dan alleen maar een taalkundige onvolkomenheid. Indien v. d. Schroeff verklaart: „Er zijn weinig betrekkingen tussen functies en functionarissen in het bedrijf, die zoveel spanningen oproepen als die tussen lijn en staf" dan geloven wij dat dit euvel, zo niet geheel dan toch wel grotendeels, wordt veroorzaakt door de heersende onduidelijkheid omtrent hetgeen als doelmatige verhouding tussen staf en lijn is aan te merken.

Ter onderstreping van het belang van deze stelling zouden wij hieraan nog willen toevoegen dat de spanningen waarop v. d. Schroeff doelt, een belangrijke hinderpaal vormen voor een succesvolle efficiency-verbetering in het bedrijf. Indien staf en lijn bij de oplossing van organisatorische vraagstukken en passant ook nog een overmaat aan spanningen moeten verwerken, dan is dat uiteraard niet bevorderlijk voor de snelheid waarmede hun gezamenlijke inspanningen met succes worden bekroond.

Alvorens de formulering van een doelmatig stafbegrip te beproeven, verdient het aanbeveling het gangbare stafbegrip ${ }^{3}$ ) aan een critische beschouwing te onderwerpen.

In de gangbare opvatting is de staf ogenschijnlijk op logische gronden gebaseerd.

1) maart 1958, no. 3.

2) In dit artikel zullen wij ons beperken tot het terrein van de administratieve organisatie, op welk terrein wij ons meer in het bijzonder thuis voelen.

3) Gedoeld wordt hier op het engere stafbegrip, en dus niet op het "verwaterde" begrip, dat ook andere niet met uitvoerende arbeid belaste functionarissen omvat.

m a b blz. 202 
Men heeft in eerste instantie een opinie gevormd over de behoeften waarin de staf zou kunnen voorzien en vervolgens heeft men een op die behoeften gerichte staf gecreëerd.

Voor wat de behoeften aan een staf betreft, bestaat vrij algemeen de opvatting, dat in de lijnorganisatie (zonder staf) de bewaking en de verbetering van de efficiency tamelijk gemakkelijk in het gedrang komt, omdat de tot beslissing bevoegde lijnchef veelal:

- in onvoldoende mate beschikt over de deskundigheid die nodig is om administratief-organisatorische problemen tot een goed einde te brengen (de deskundigheidsfactor);

- bovendien te zeer in beslag wordt genomen door zijn uitvoerende taken om zich in voldoende mate bezig te kunnen houden met de efficiency van de aan hem toevertrouwde taken (de tijdsfactor);

- voorts geen voldoend duidelijk overzicht heeft van het gebeuren door de gehele produktiekolom van het bedrijf heen en trouwens in niet door hem beheerde gebieden van het bedrijf geen vrije toegang heeft de (de coördinatiefactor);

- tenslotte niet de mentaliteit heeft die wenselijk is voor het aanpakken van ef ficiencyproblemen (de mentaliteitsfactor).

Waar men met het oog op de gewenste eenheid in de bevelvoering, de lijn niet wilde ontheffen van de beslissingsbevoegdheid, was deze bevoegdheid voor de staf niet meer ter beschikking. Dit zo zijnde, leek het logisch de taak van de staf een adviserend karakter te geven. Evenzeer was het logisch de staf op zodanige wijze samen te stellen, dat zij kon voorzien in de vorengeschetste behoeften.

Uit deze opvatting kwam een stafbegrip naar voren, dat kan worden weergegeven door een citaat uit de beschouwing van v. d. Schroeff:

.,Het kenmerk van de staf is, dat zij niet in de commandolijn staat, hetgeen inhoudt, dat er geen gezagsverhouding is van de staf ten opzichte van de lijnfunctionarissen. De staf treedt niet als opdrachtgever van de uitvoerende functionarissen op. $Z_{\mathrm{ij}}$ legt alleen een project voor of dient van advies, dat eerst dan een dwingende aanwijzing voor de uitvoering vormt, indien het door de betrokken leider in de "lijn" is geautoriseerd. Vrijwel de gehele literatuur beklemtoont dat de verhouding van staf tot uitvoering alleen adviserend, informerend en coördinerend moet zijn."

$\mathrm{Nu}$ ligt het in de lijn van het doelmatig organiseren om het nuttig effect van een getroffen maatregel aan een critisch onderzoek te onderwerpen.

Doet men dit met betrekking tot de instelling van een staforgaan, dat is gebaseerd op het gangbare stafbegrip, dan komt men tot de conclusie, dat de staf- en lijnorganisatie gebreken vertoont, waarvan de schadelijke werking voor het bedrijf in het voorgaande al werd onderstreept.

Hoewel de bovenaangehaalde karakteristiek van de staffunctie de theoretische verhouding tussen lijn en staf op juiste wijze weergeeft, zijn er toch redenen om te betwijfelen, of dit begrip op doelmatige wijze in practijk wordt gebracht.

Meer in het bijzonder gaat het daarbij om de interpretatie van de karakteristieke bestanddelen van de staffunctie, nl. de adviserende, de informerende en de coördinerende. De twijfel aan de doelmatige beoefening in de practijk van de aldus geschetste functie van de staf wordt gerechtvaardigd door de veelal onbevredigend geachte verhoudingen die tussen lijn en staf bestaan. Immers men constateert dat de staf een latente neiging vertoont 
om te ontsnappen aan de regels die zijn geformuleerd in het gangbare stafbegrip (alleen adviseren, niet beslissen) en men constateert dit terecht met een zeker misnoegen, omdat de gevolgen van deze ontsnappingspogingen in strijd zijn met de belangen van het bedrijf.

$\mathrm{Nu}$ kan het ongewenste gedrag van de staffunctionaris twee oorzaken hebben:

a. de functionaris zou het voorschrift wel kunnen opvolgen, maar om hem moverende redenen wenst hij dit niet;

b. het voorschrift is ondoelmatig en kan redelijkerwijs niet door de functionaris (volledig) worden nageleefd.

Als - om een enigszins grotesk voorbeeld te gebruiken - bij een militaire oefening zou worden bepaald, dat de troep het beste de overkant van een kanaal kan bereiken door er over heen te springen en de ervaring leert vervolgens dat alle soldaten in het water terecht komen, dan is er - naast de mogelijkheid van onwil der soldaten - ook nog de kans te overwegen dat het kanaal te breed is en het beginsel dat aan de opdracht ten grondslag ligt, ondoelmatig is.

Zo dient de ervaring met de staf in de practijk van het bedrijfsleven aanleiding te zijn om het in de practijk gangbare stafbegrip niet voor axiomatisch juist te houden, zolang niet is nagegaan of niet een beter stafbegrip is te vormen, dat dus de ondervonden moeilijkheden niet of althans in mindere mate tengevolge heeft.

Deze nadere vorming van het begrip „staf" dient dan plaats te vinden op basis van een hernieuwde overweging van de behoeften aan de medewerking van een staf bij de oplossing van administratief-organisatorische problemen en met inachtneming van de ervaringen die inmiddels in de practijk zijn opgedaan.

Ten aanzien van de begripsvorming is het in dit geval niet overbodig op te merken, dat de staf een in het bedrijf gecreëerde functie is. De topleiding heeft het dus in de hand deze functie (en daarmede het stafbegrip) de inhoud te geven, die in overeenstemming is met de belangen van het bedrijf.

Deze opmerking is van belang, omdat het woord ,staf" is ontleend aan de militaire organisatie, hetgeen er gemakkelijk toe zou kunnen leiden om de langduriger ervaringen met de staf aldaar als toonaangevend voor de bedrijfsorganisatie aan te merken. Ofschoon het niet onmogelijk is, dat zekere ervaringen in de militaire organisatie ook hun nut afwerpen voor de oplossing van het organisatieprobleem in de bedrijven, dient men zich wel bewust te zijn, dat de verschillen tussen aard en doeleinden van de militaireen bedrijfsorganisatie zo diep gaan, dat de voor het leger gevonden waarheden niet dan met de grootste reserve door de bedrijfsleiders mogen wor den overgenomen.

Sprekend over de administratieve organisatie geldt deze reserve in niet mindere mate voor de ervaringen, die met het stafprobleem zijn opgedaan in de industrie. In feite houdt een belangrijk deel van de literatuur op dit gebied zich bezig met de organisatievraagstukken in de fabriek. Hoewel in bedrijfs-economische zin ook de administratie een tak van voortbrenging is (door de productie van gegevens en documenten), zijn de verschillen tussen de administratieve en de fabriekmatige voortbrenging te groot, dan dat de voor het fabrieksproces gevonden wetmatigheden als zonder meer geldend voor de administratie kunnen worden overgenomen.

Zoals gezegd zal de topleiding van de administratie bij de bepaling van het doelmatige begrip "staf" uitsluitend de belangen van de administratie voor ogen moeten houden.

m a b blz. 204 
Daaruit vloeit als eerste eis voor het te vormen stafbegrip voort, dat het bij toepassing in de practijk, een maximaal rendement moet kunnen afwerpen.

Om redenen die wellicht op deze plaats niet uitvoerig besproken behoeven te worden, zullen wij er voorshands van uitgaan, dat bij de bepaling van het stafbegrip niet moet worden getornd aan de beslissingsbevoegdheid van de lijn.

Voor een dergelijk uitgangspunt pleit niet alleen de wenselijkheid van de eenheid der bevelvoering, van niet minder belang is de ervaring, dat de uitvoering aan kwaliteit wint, indien de met de uitvoering belaste functionarissen zichzelf in hun werk (d.w.z. in de door hen zelf genomen beslissingen) kunnen terugvinden.

Aldus komt reeds vast te staan, dat de staffunctie een complementair karakter zal moeten hebben, in deze zin dat zij aanvullend optreedt, daar waar de lijn niet in staat is het volle pond te leveren.

Daaruit volgt, dat het ter bepaling van het doelmatige stafbegrip in de eerste plaats noodzakelijk is een nauwkeurig inzicht te hebben in de gebieden die de lijn als regel niet of niet volledig beheerst.

Welke gebieden zijn dit? Wij hebben reeds gezien dat als regel een viertal factoren in ogenschouw worden genomen, te weten:

- de deskundigheidsfactor

- de tijdsfactor

- de coördinatiefactor

- de mentaliteitsfactor.

Het is dienstig elk van deze factoren aan een nadere beschouwing te onderwerpen.

\section{De deskundigheidsfactor}

Administratief-organisatorische problemen hebben meestal een veelzijdig karakter. Niet alleen moeten technische puzzles worden opgelost, maar ook moet rekening worden gehouden met de vraag of een bepaalde oplossing past in het beleid van het bedrijf en of en welke repercussies die oplossing zal hebben in het psychologische vlak.

De beschouwing van elk dier aspecten vereist ervaring en inzicht op uiteenlopende gebieden, zodat in wezen bij de oplossing van dergelijke problemen een beroep gedaan moet worden op verschillende deskundigheden.

De mate waarin een afhankelijkheid bestaat van elk dier deskundigheden verschilt van bedrijf tot bedrijf en zelfs van geval tot geval. Het is dus niet mogelijk de deskundigheidsfactor in algemene zin zodanig te evalueren, dat voor ieder bedrijf en voor ieder geval afzonderlijk een volledig recept al bij voorbaat gereed ligt. Noodgedwongen zal een critische beschouwing van de deskundigheidsfactor dus een generaliserend karakter moeten hebben.

Indien wij ons nochtans, ter verduidelijking van de conclusie waartoe deze beschouwing wil voeren, aan een dergelijke generalisatie wagen, dan zouden wij drie punten op de voorgrond willen stellen.

1e. Bij de oplossing van problemen van administratief-organisatorische aard bestaat veelal behoefte zowel aan een deskundigheid omtrent de ontwikkeling en de stand der administratieve organisatie in het verleden en het heden (kortweg een retrospectieve deskundigheid) als aan een deskundigheid omtrent de mogelijke ontwikkeling van de administratie in de toekomst (kortweg een prospectieve deskundigheid). 
2e. Normaliter zal voor de zich in de practijk voordoende problemen de retrospectieve deskundigheid in de lijn aanwezig zijn. Evenwel mag niet verwacht worden, dat de lijn ook op alle gebieden ",prospectief" deskundig is.

3e. In de mate waarin dit laatste niet het geval is, bestaat er derhalve behoefte aan een aanvulling. Het is deze aanvulling die als taak aan de staf toevalt.

Het onderstaande overzicht, dat generlei aanspraak maakt op volledigheid, kan deze stellingen illustreren.

Benodigde retrospectieve deskundigheden

Benodigde prospectieve

deskundigheden

Technische aspecten van efficiency-problemen

- Practische aanpak van taken

- Finishing touci van bestaande procedures

- Bedieningsvaardigheden

- Kennis van het practisch rendement van bestaande hulpmiddelen

- Organisatie van toelevering en aflevering

- Inzicht in nog niet in de practijk gebrachte mogelijkheden met name t.a.v.

- concrete hulpmiddelen (diverse administratiemachines, boek. houdmachines, bandvervaardigende machines, electronische apparatuur), verder diverse systemen als kaartsystemen, doorschrijfsystemen, enz.

- abstracte hulpmiddelen zoals werkmethoden, budgetering, statistische hulpmiddelen, taakanalyse, prestatiemeting, probleemoplossingsmethoden, etc.

\section{Beleidsaspecten van efficiencyproblemen}

- Soepele toepassing van bestaande beleidsregelen, zowel in normale als bijzondere gevallen

- Practische mogelijkheden in het bestaande beleid

- Kennis van de reactie van bepaalde relaties op bepaalde beleidsregelen
- Inzicht in de mogelijkheden van beleidsvernieuwingen, al dan niet in samenhang met wijzigingen in de afzetmarkt, de toeleveringsmarkt en de arbeidsmarkt

- Inzicht in mogelijkheden van zich binnen of buiten het bedrijf ontwikkelende nieuwe denkbeelden

Psychologische aspecten van efficiency-problemen

- Kennis van eigenschappen en kundigheden van het bestaande personeel

- Vaardigheid in het rendabel aanwenden van die eigenschappen en kundigheden

- De ",persoonlijke" band met het

- Inzicht in de nieuwe mogelijkheden van personeelsaanpak

- Toepassing hiervan bij concrete bedrijfsvraagstukken (bv. opleiding, bedrijfsdiscussies, probleemoplossingen, werkverdeling) bestaande personeel

Om iedere misvatting bij voorbaat weg te nemen, zij hier nogmaals onderstreept, dat de verdeling in deze beide groepen van deskundigheden in 
hoge mate schetsmatig is. Er zijn ongetwijfeld voorbeelden aan te halen van gevallen waarin de lijnfunctionaris zich ook geheel of ten dele thuis voelt op het terrein dat in de rechterkolom wordt aangeduid. Omgekeerd beschikken vele staffunctionarissen ook over verschillende ",retrospectieve" kundigheden.

Anderzijds zal niet ontkend kunnen worden dat het geschetste beeld als typering voor normale gevallen opgaat en in sterkere mate opgaat naarmate het bedrijf groter is, ingewikkelder is en dynamischer is.

Er werd al vooropgesteld dat het doelmatig is de taak van de staf te doen bestaan in het opvullen van de lacunes in de lijn en dat deze lacunes veelal zullen liggen ter rechterzijde van de hierboven getrokken streep.

Bij deze stelling kunnen nu nog enkele kanttekeningen worden geplaatst:

a. Geheel afhankelijk van een bestaande situatie zal zijn of en in welke mate de inschakeling van de staf doelmatig is en of er één of meerdere staven zullen zijn. Denkbaar is in een grote organisatie afzonderlijke staven voor aparte branches van een concern, voor automatiseringsvraagstukken, voor bedrijfspsychologische vraagstukken, enz.

b. De normale probleemoplossing zal bij het optreden van de staf zijn, dat deze zich met de lijn "verenigt" in een team, waarin de inzichten (ter weerszijden van de streep) worden verweven tot één integraal inzicht.

Voor de doelmatige verhouding tussen lijn en staf is de laatste kanttekening naar onze mening van groot belang. De kenmerkende functie van de staf t.o.v. de lijn is niet adviserend of informerend, doch samenwerkend en aanuullend.

Het onderscheid tussen adviseren en aanvullen moge ogenschijnlijk van graduele betekenis zijn, in wezen is dit onderscheid echter elementair.

Adviezen worden gegeven door een deskundige aan een niet-deskundige, of door een meer-deskundige aan een minder-deskundige. $\mathrm{Nu}$ is, zoals het vorenstaande heeft willen onderstrepen, onjuist te stellen, dat de deskundigheid een eigenschap is van de staf, waarin zij zich van de lijn onderscheidt. Door - wederom in het normale geval - de staf het aureool van deskundigheid of meerdere deskundigheid te geven (via een adviserende taak) heeft men de staf bekleed met een functie die zij niet volledig kan waarmaken. Immers, ook de lijn is deskundig - zij het op andere gebieden en de voorstelling van de staf als een instelling die het beter weet, althans beter behoort te weten, moet wel verzet in de lijn oproepen, wier eigen deskundigheid op deze wijze wordt gebagatelliseerd.

Indien echter van meet af aan de staf als partner wordt toegevoegd, indien, door een verstandige introductie van de staf, de lijn zich ook als partner gedraagt, is een kwaadaardige stekel uit dit zo moeilijke en belangrijke bedrijfsprobleem verwijderd. In het partnership of het team dat lijn en staf behoren te vormen, treedt de individuele bijdrage die ieder aan de oplossing geeft op de achtergrond: de oplossing wordt gevonden door het team.

De vraag kan nog rijzen waarom de lijn niet tot doelmatige beslissingen zou kunnen komen indien zij haar eigen opvattingen vergelijkt met die welke zijn neergelegd in een advies van de staf.

Het antwoord op die vraag moet $z$ ijn dat administratief-organisatorische vraagstukken als regel van zo ingewikkelde aard zijn, dat een dergelijke procedure practisch om verschillende redenen onuitvoerbaar is:

1e. Het is onwaarschijnlijk dat alle overwegingen die de lijn van belang 
acht voor een bepaald onderwerp door de staf in het advies zijn betrokken.

$2 e$. Het is de vraag voorts of de lijn alle consequenties van het ",advies" van de staf volledig kan overzien.

$3 e$. Het is tenslotte de vraag of de staf zijn advies ongewijzigd zou laten, als alle overwegingen en bedenkingen van de lijn bekend waren.

De doelmatige oplossing is dus niet advies van staf aan lijn, maar teamwerk van staf en lijn tezamen.

Heeft de staf een taak in een gedecentraliseerde organisatie, waarin de afzonderlijke organen (bijv. bijkantoren van banken of verzekeringmaatschappijen) alle volgens eenzelfde takenpatroon dienen te werken, dan kan de taak van de staf iets anders komen te liggen. In dergelijke organisaties heeft de taak van de lijn meer het karakter van uitvoering van door anderen genomen besluiten en van nature zal het aandeel van de staf in de besluitvorming belangrijker zijn. Dit neemt niet weg. dat ook in die gevallen een doelmatig overleg tussen staf en lijn als regel aangewezen is.

Het is intussen interessant om op te merken, dat de staf in dergelijke situaties in, of heel dicht bij, de commandolijn kan komen te staan. De door de literatuur beklemtoonde stelling dat aanwijzingen voor de uitvoering onder alle omstandigheden uit de lijn zelf moeten stammen, is dus niet in alle opzichten in overeenstemming met de practijk.

\section{De tijdsfactor}

Een ervaring is dat de lijnchef dikwijls zozeer door zijn uitvoerende taken in beslag wordt genomen, dat hij geen tijd heeft zich in voldoende mate met de organisatorische problemen van zijn afdeling bezig te houden. Hieruit resulteert dan de behoefte om een staf aan te stellen die deze taak uit handen van de chef kan nemen.

$\mathrm{Na}$ de vorenstaande uiteenzetting is het waarschijnlijk niet meer nodig om uitvoerig uiteen te zetten, dat deze conclusie bij een critische beschouwing van de behoeften geen stand kan houden.

Reeds werd duidelijk:

a. dat bij tal van problemen de deskundigheid van de lijn niet kan worden gemist;

b. dat de deskundigheden van lijn en staf moeten worden samengesmolten om tot een doelmatige oplossing te komen.

Beide overwegingen zullen ertoe moeten leiden dat de lijnfunctionaris een deel van zijn tijd voor de oplossing van organisatievraagstukken vrij makkt.

$\mathrm{Nu}$ neemt het vorenstaande niet weg dat veel lijnchefs inderdaad onder een chronisch tijdsgebrek gebukt gaan (niet zelden tengevolge van de gebrekkige organisatie van hun afdeling en waardoor relatief veel tijd moet worden besteed aan het oplossen van moeilijkheden) en somtijds zullen dus maatregelen genomen moeten worden om de lijnchef vrij te maken voor het overleg op organisatorisch gebied.

Overigens kan de staf wel trachten in overleg met de lijn zekere voorbereidende werkzaamheden uit handen van de lijnchef te nemen. Veelal is dat het geval met de verzameling van de nodige gegevens die bij de probleemoplossing moeten worden geraadpleegd.

Indien ook dan de lijnchef zich nog niet in de aanvankelijk gewenste mate kan vrijmaken voor deze organisatorische arbeid, dan zal dit in vele 
gevallen nog geen overmatige bezwaren opleveren omdat de staf zijn tijd dan kan verdelen over een aantal problemen die zich op verschillende afdelingen voordoen. Op deze wijze wordt het front van de aanval op de inefficiency in het bedrijf wat breder zij het wat minder diep.

Het rendement van de inspanningen ter bevordering van de efficiency behoeft daaronder nog niet te lijden.

Uit een en ander volgt dat de behoefte die wij als de ,tijdsfactor" hebben aangeduid, maar zeer ten dele aanleiding kan geven tot de instelling van een staforgaan.

\section{De coördinatiefactor}

Kon aan de tijdsfactor als behoefte tot het instellen van staforganen geen grote betekenis worden toegekend, geheel anders ligt dit bij de behoefte aan coördinatie.

Uiteraard zal die behoefte groter zijn naarmate de administratie een meer gecompliceerd karakter heeft, maar gezien het feit, dat de gecompliceerdheid der administraties eerder toe- dan afneemt, zal deze factor in het algemeen van groot belang zijn.

In het algemeen kan men stellen:

a. dat in een bedrijf in laatste aanleg niet interessant is of een bepaalde maatregel winst of verlies op één bepaalde afdeling oplevert; belangrijk is of die maatregel voor het bedrijf als totaliteit een voordeel betekent;

b. dat in een gecompliceerd bedrijf een maatregel op een bepaalde plaats voor de niet geheel ter zake kundige soms ongedachte repercussies op andere plaatsen in het bedrijf tengevolge kan hebben.

Het ligt in de aard der zaak dat de lijnchef meer deskundig is op zijn eigen terrein dan op het terrein van andere afdelingen.

Indien echter zoals veelvuldig geschiedt bij een bepaald administratieforganisatorisch probleem meerdere afdelingen zijn betrokken, bestaat er bij de oplossing van dit probleem behoefte aan een inzicht in de betekenis van denkbare oplossingen voor het bedrijf als geheel, d.w.z. voor alle afdelingen.

Te dezen opzichte vertoont de lijn dus weder een manco, dat dientengevolge dient te worden gecompenseerd door deskundigheid bij de staf.

Uit die taak vloeit een plicht voort voor de lijn om de staf in te lichten over alle maatregelen die gevolgen kunnen hebben die verder reiken dan de afdeling waar die maatregel wordt getroffen.

Beter ware zelfs die plicht uit te strekken tot alle organisatorische maatregelen in de lijn, niet alleen omdat de lijn niet altijd kan beoordelen welke gevolgen bepaalde maatregelen elders kunnen opleveren, maar ook omdat de staf zeer wel profijt kan trekken van zekere vindingen in de lijn, ten behoeve van andere lijnafdelingen.

\section{De mentaliteitsfactor}

Als laatste factor die een rol speelt bij de bepaling van de behoefte aan een aanvullend staforgaan, noemden wij de mentaliteitsfactor.

Men zegt wel dat voor de oplossing van organisatorische problemen een andere mentaliteit nodig is, dan die welke aanwezig is bij de pur sang lijnchef.

Hoe gevaarlijk het ook moge zijn om te generaliseren als het gaat om menselijke eigenschappen, de geponeerde stelling heeft een kern van waar heid. 
De „pur sang" lijnchef beoogt de uitvoerende macht in de perfectie te beoefenen (en wij gebruiken het woord perfectie dan niet in de denigrerende betekenis, die is verbonden aan het begrip perfectionisme). $\mathrm{Nu}$ is "uitvoeren" doen wat is voorgeschreven; de uitvoering is gebaseerd op de regels die gegeven zijn door de wetgevende macht. Het lijdt geen twijfel dat uitvoering in deze letterlijke zin perfecter kan zijn naarmate de regels die als grondslag voor de uitvoering dienen een meer standvastig karakter hebben. Een wijziging in de regel betekent een ,incident" met betrekking tot de uitvoering.

De „pur sang"lijnchef is - bij overdrijving gezegd - om die reden gekant tegen wijziging van zijn spelregels, die hem voor andere problemen plaatst dan die welke hij bij de uitvoering van de standvastige regels ontmoet. De grond wordt hem a.h.w. onder de voeten weggehaald.

Om deze en andere redenen treedt de lijnchef van nature gemakkelijk op als de beschermer van de continuiteit in het bedrijf. Uit de bedrijfseconomische literatuur is trouwens bekend dat de continuïteit een factor van betekenis is bij de beschouwing van organisatorische problemen en het is stellig voor het bedrijf een zeker voordeel dat er functionarissen zijn die voor het nut van de continuitteit oog hebben.

Anderzijds is bekend dat de efficiency in het bedrijf in hoge mate kwetsbaar is. Verbetering van de efficiency vereist een visie op de mogelijkheden hoe het beter zou kunnen en dus een critische instelling t.o.v. het bestaande.

De ,pur sang" organisator weet a.h.w. instinctief dat vrijwel iedere procedure kan worden verbeterd. Hij speurt voortdurend naar gebreken enerzijds en naar betere oplossingen anderzijds. Het ligt min of meer in zijn aard om voortdurend te slopen en te herbouwen.

Een andere mentaliteitsfactor die van belang is bij de stafman is dat deze er van doordrongen moet zijn dat de leidinggevende mens niet gesteld is op inmenging. In zekere $z$ in is iedere inmenging hoe ook genaamd, een aantasting van de zelfstandigheid. Dit alles heeft tot gevolg dat de stafman niet verwacht dat hij zonder meer wordt aanvaard. $H_{i j}$ weet dat hij anderen voor zich moet winnen; hij moet mentaal bereid en in staat zijn dat te doen.

\section{Het doelmatige stafbegrip}

In het vorenstaande is nu voldoende stof verzameld om op grond van een critische beschouwing der behoeften een nauwere begrenzing van het staf begrip te beproeven.

1. Het lijn - en stafsysteem als structuurvorm voor de administratieve organisatie is alleen doelmatig indien de lijn wel een relevante, echter redelijkerwijs niet een volledige, bijdrage kan leveren voor de oplossing van de organisatieproblemen. Liggen de verhoudingen in het bedrijf anders dan dient een andere organisatiestructuur te worden gekozen.

2. In de doelmatige lijn- en staforganisatie heeft het stafbegrip een plastisch karakter. De staf heeft in de meest algemene zin tot taak om ten aanzien van administratief-organisatorische problemen, samen met de lijn een team en - zo men wil voor ieder geval apart, een team ,,ad hoc" - te vormen, dat zich tot plicht rekent het gestelde probleem op de meest doelmatige wijze op te lossen. De bijdrage die staf en lijn in dit team leveren wordt bepaald door de aard van het probleem en door de deskundigheden die bij staf en lijn aanwezig zijn. Een voorwaarde hiervoor is dat de staf open oor heeft voor de lijn en de lijn voor de staf.

$\mathrm{m} \mathrm{a} \mathrm{b}$ blz. 210 
3. De mogelijkheid om langs die weg tot een goed resultaat te komen bestaat alleen als tussen lijn en staf een goede verstandhouding bestaat. Het ligt op de weg van staf en lijn beide, maar in de eerste plaats op de weg van de topleiding en de staf zelf, om middelen te beramen om die verstandhouding op het gewenste peil te brengen.

4. De aard van het resultaat van het staf-lijnteam kan wellicht het best worden getekend door de eis, dat dit resultaat geen compromis moet zijn, maar een synthese.

5. De samenwerking tussen lijn en staf is in verband met de veelheid van mogelijkheden vormvrij, in het algemeen genomen zullen lijn en staf in gemeen overleg de methoden en middelen die in het ,teamverband" voor de probleemoplossing worden gebruikt, bepalen.

6. Maatregelen dienen te worden genomen, dat de staf wordt betrokken bij alle organisatorische maatregelen in de lijn, althans bij die maatregelen, die ook gevolgen voor andere afdelingen kunnen hebben.

\section{De introductie van het stafbegrip}

Indien wij er in geslaagd zouden zijn het stafbegrip op doelmatige wijze te bepalen, dan dient hierbij nog wel te worden aangetekend dat dit begrip betrekking heeft op volmaakte verhoudingen tussen lijn en staf.

De volmaaktheid is evenwel een eigenschap die aan de werkelijkheid vreemd is. Op zijn best kan men dan ook verwachten steeds dichter naar doelmatige lijn-stafverhoudingen toe te groeien. Hierbij is echter een weloverwogen politiek bij de indoctrinatie van het doelmatige stafbegrip een elementaire voorwaarde.

Immers de heersende - en tot spanning aanleiding gevende - misvattingen omtrent doelmatige lijn-stafverhoudingen zijn niet alleen van theoretische aard. De achtergronden van dergelijke spanningssituaties worden in de practijk grotendeels bepaald door (vermeende) bedreiging van persoonlijke belangen, zowel aan de kant van de lijn als van de staf.

Indien van der Schroeff in zijn eerder aangehaalde beschouwing zegt: .Om het zo concreet mogelijk te stellen: men late de staf nimmer op de lijn los!", dan onderschrijven wij die stelling geheel en al voor de staf die een onjuiste opvatting heeft van zijn taak, in die zin dat hij tracht zijn denkbeelden in de practijk te brengen, zonder het noodzakeliike overleg met de lijn. Ongetwijfeld heeft de geciteerde uitspraak ook op die staf betrekking.

De doelmatig werkende staf behoort zich echter nimmer in een situatie te begeven, waarin voor deze uitspraak aanleiding kan komen te bestaan. De openlijke of verkapte greep naar de uitvoerende macht door de staf is zo strijdig met doelmatige bedrijfsverhoudingen dat inderdaad de staf die zich daaraan waagt, desnoods op duidelijke wijze aan banden gelegd moet worden.

De staf daarentegen die zich wèl op juiste wijze van zijn taak kwijt - en wij hebben getracht in het vorenstaande die taak te schetsen - dient uiteraard in termen van volledige openheid met de lijn te kunnen communiceren.

Bij een doelmatige taakvervulling door de staf zal de lijn op de duur ook niet het gevoel krijgen dat de staf op haar is "losgelaten". Integendeel de lijn zal gaandeweg die medewerking op prijs stellen en de medewerking van de staf waar nodig inroepen. Dat die situatie dikwijls pas als de uitkomst van een zeker groeiproces, ten tijde waarvan de staf het vertrouwen van de lijn moet winnen, optreedt, zal geen nader betoog behoeven.

Hetzelfde geldt voor de regel die van der Schroeff geeft voor collisies tussen staf en lijn: „...... Dit houdt in dat bij collisie van een aanwijzing 
van uit de lijn en van uit de staf, de aanwijzing van de lijn moet worden gevolgd, alles onverminderd "het hoger beroep" van de staf".

Wederom, de staf behoort qualitate qua géén opdrachten aan lijninstanties te geven. Doet de staf dit wél, dan dient met het oog op de consequenties al terstond te worden ingegrepen. Op dit punt zouden wij zelfs een stap verder willen gaan dan van der Schroeff. Bij voorbaat moet worden voorkomen dat de staf opdrachten geeft, ongeacht de vraag of de lijn zich daarmede achteraf blijkt te verzoenen of niet. Wij vrezen nl. dat de eerste stap van de staf in die richting tegelijkertijd de eerste stap is op een hellend vlak dat leidt naar onjuiste verhoudingen in het bedrijf.

Is dus de ondoelmatig werkende staf een latent gevaar, waartegen op ieder critisch moment een wal moet kunnen worden opgeworpen, de doelmatig werkende staf is een nuttig en daarom noodzakelijk instituut, dat overigens zijn werk moet doen in een klimaat dat ten dele (nog) wordt beheerst door een aantal misvattingen, aan het ontstaan waarvan de staf zelf niet zelden een bijdrage heeft geleverd.

Voor die situatie dienen zij die in de practijk met staf en lijn te maken hebben open oog te hebben.

Het vorenstaande betekent allerminst dat iedere bedrijfsgenoot er op uit moet zijn coûte que coûte een koek-en-ei stemming tussen staf en lijn te kweken.

Het is zeer wel mogelijk, en somtijds ook niet te vermijden, dat staf en lijn divergeren ten aanzien van door de lijnchef in de lijn te geven opdrachten. In zulk een geval kan hoger beroep op de topleiding de enige uitweg zijn.

Dit „hoger beroep" zal dan niet het karakter moeten hebben van een min of meer formele rechtspraak, waarbij de topleiding op basis van gewisselde nota's of rapporten, uitspraak doende, de een gelijk geeft en de ander ongelijk. Een dergelijke methode schept vrij zeker frustraties bij de in het ongelijk gestelde.

Veeleer is aanbevelenswaardig, dat de topleiding ad hoc toetreedt tot het overleg tussen staf en lijn. Daarbij zal zij in de eerste plaats de situatie moeten ontdoen van een overmaat aan spanningen en op een herstel van doelmatige verhoudingen in het ,teamverband" aansturen, waarbij dus (vermeende) persoonlijke belangen of prestige-kwesties naar de achtergrond worden verwezen. Een wijs beleid bij dergelijke moeilijkheden zal naar wij geloven, staf en lijn gaandeweg op het pad naar doelmatige bedrijfsverhoudingen brengen.

Overigens ligt het o.i. in de eerste plaats op de weg van de staf om bewust naar dergelijke doelmatige verhoudingen toe te werken door het cultiveren van alle factoren die te dezer in positieve zin werken (zie hierboven).

Dit betekent niet, - het zij nogmaals gezegd - dat de staf elke spanning met de lijn uit de weg moet gaan. Dit zou tot een politiek van vrede tot elke prijs kunnen leiden die voor de efficiency-verbetering niet aanbevelenswaardig is.

Grote problemen worden veelal niet opgelost, als er niet af en toe een sterke druk op komt te staan, dit kan zeer wel met zekere spanningen gepaard gaan. Verkeerd is evenwel als dergelijke spanningen boven de tolerantie uitgaan en niet worden afgewisseld door ontspanningen.

In normale gevallen is deze spanningstolerantie gelegen bij het punt waar een enigszins durzame wrevel de goede verhoudingen in het bedrijf zou gaan schaden.

m a b blz. 212 